\title{
The effects of maternal nutrition around the time of conception on the health of the offspring
}

\author{
MHOliver, AL Jaquiery, FH Bloomfield and JE Harding \\ Liggins Institute, University of Auckland, Auckland, New Zealand
}

\begin{abstract}
The incidence of prematurity, diabetes and cardiovascular disease have been increasing in both the developed and developing world. Increasing numbers of human studies suggest that these serious health outcomes may have developmental origins originating from nutritional deficits in the periconceptional period, with maternal nutrition around the time of conception now shown to have important effects on the length of gestation, trajectory of fetal growth and on postnatal growth and health. Biomedical research using the pregnant sheep has been widely employed to gain a deeper understanding of the underlying mechanisms involved. There is growing awareness that this field of research has major implications for the livestock production industry. From our own studies on sheep we have evidence that maternal undernutrition during the periconceptional period results in altered fetal hypothalamic-pituitary-adrenal axis (HPAA) development, an increased rate of premature birth, altered fetal pancreatic function, insulin signalling and amino acid metabolism, and also alterations in maternal adaptation to pregnancy. We are currently studying the postnatal consequences of these changes. Other research groups have shown that restricted nutrition of sheep in the early part of pregnancy alters postnatal muscle development, fat deposition, cardiovascular regulation and HPAA function. One aim of this review is to illustrate how biomedical research using animals such as the sheep has been used to gain a better understanding of the consequences of reduced maternal nutrition during the periconceptional period. We suggest that there are equally important consequences of this research for the livestock production industries.
\end{abstract}

\section{Introduction}

Maternal nutrition, and particularly undernutrition, has been recognised as an important influence on the growth and metabolism of the offspring. A large amount of research has focused on the effects of maternal undernutrition in late pregnancy. However the effects of undernutrition around the time of conception are now a major focus of both biomedical and agricultural research. There is increasing epidemiological evidence from human populations to suggest that poor maternal nutrition around the time of conception or in early pregnancy may lead to a higher incidence of premature birth (Rayco-Solon et al. 2005) and an increased risk of developing hypertension, heart disease and obesity later in adult life (Roseboom et al. 2001a; Gluckman 
et al. 2005). In the sheep, maternal nutrition around the time of conception has an important influence on the development of the conceptus in terms of its growth, physiology (Oliver et al. 2005) and the length of gestation (Bloomfield et al. 2003). The implications for livestock production parameters such as fat and muscle development are an important area of current research.

The focus of this review is to discuss the importance of maternal nutrition at the time of conception on fetal development, offspring survival, and for postnatal growth and development. Other factors, such as the hormonal environment at the time of conception are also recognised to have profound effects on the development of the offspring (Kleemann et al. 2001). Similarly, experiments using in vitro culture of embryos have indicated powerful effects of the local nutrient environment, leading to alterations in cell number and allocation to different embryonic cell lines and hence altered fetal and placental growth (Barnes 2000). It is beyond the scope of this review to discuss these other periconceptional factors except where they shed light on possible mechanistic aspects of nutritional effects. Rather, we will concentrate on the effects of maternal undernutrition around the time of conception on fetal growth, fetal hypothalamic-pituitary adrenal axis (HPAA) development, insulin secretion and signalling, regulatory physiology, maternal adaptation to pregnancy and the possible postnatal consequences of all of these factors. We have recently demonstrated that late gestation twin fetal sheep of ewes that were well nourished throughout pregnancy demonstrate a similar physiological phenotype to singleton fetuses of ewes that were undernourished around the time of conception. As twinning is an important aspect of commercial sheep breeding, we will also overview the consequences of twinning for many of these outcomes.

\section{Fetal growth}

Early studies of the relationship between fetal growth and later disease risk came from cohort studies of British populations born in the 1920s (Hales et al. 1991). Careful follow-up revealed that men and women of lower birth weight had higher blood pressure, increased risk of coronary heart disease (Fall et al. 1995) and impaired glucose tolerance as adults (Phipps et al. 1993; Law 1996). These initial findings by Barker and colleagues were soon replicated in many other populations, establishing a strong and consistent link between size at birth and the incidence of diabetes (Fall et al. 1998; Ravelli et al. 1998) and cardiovascular disorders in later life (Barker, 2000). However it was less clear whether it was small birth size itself, or the cause of that small size, that was most important in determining outcome.

One cause of small size at birth in many animal species is maternal nutritional intake inadequate for fetal demands. In human pregnancy, maternal undernutrition, if present, is often chronic and confounded by other factors such as poverty and infection, both before and after birth. The effect of different timings of severe undernutrition in a previously well nourished human population have been described in a cohort subjected to the Dutch Hunger winter. Towards the end of world war II the occupying German forces imposed embargos of food supplies in response to continued Dutch resistance efforts, and severe famine resulted for 5 months before the lifting of the blockade by the Allied forces. Very good data were collected on the timing and nature of the food rationing, and also most importantly on the babies born during the period. Those babies have now been followed into adult life, providing a unique insight into the effect of maternal undernutrition at different periods of pregnancy on the size and health of the offspring. Babies of women exposed to famine conditions only in late pregnancy had reduced size at birth, and impaired glucose tolerance as adults (Ravelli et al. 1998). However babies of women who conceived during the famine, that often extended well into 
the first trimester, were of normal size at birth, but as adults were at increased risk of coronary heart disease (Roseboom et al. 2001b), hyperlipidaemia (Roseboom et al. 2000) and obesity (Ravelli et al. 1999). These and many other studies strongly suggest that events around the time of conception can have life long effects on the offspring, without necessarily affecting size at birth. Furthermore, altered size at birth does not appear to lie on the causal pathway between reduced nutrition in early pregnancy and its consequences before or after birth.

We have examined the effects of maternal undernutrition during different periods of pregnancy in sheep, where fetal growth trajectory can be monitored from day to day using surgically implanted catheters. In late gestation, rapidly growing fetuses slowed their growth promptly in response to maternal undernutrition designed to reduce maternal blood glucose concentrations by $30-40 \%$ (Harding 1997). However, fetuses whose mothers had also been moderately undernourished around the time of conception (60d before to $30 \mathrm{~d}$ after mating to produce a 10 $15 \%$ reduction in maternal weight) grew more slowly in late gestation, and were able to continue this slow growth trajectory in the face of further severe maternal undernutrition in late gestation. These data suggest that both trajectory of fetal growth, and also the feto-placental capacity to adapt to a late gestation nutritional insult, are determined by events around the time of conception. Intriguingly, although trajectory of fetal growth was affected by periconceptional undernutrition, gross fetal size (weight and length) were not different at the end of the experiment, consistent with the human data from the Dutch Hunger Winter. However, the fetuses of periconceptionally undernourished ewes had altered body composition, with proportionately larger hearts, livers and kidneys (Harding 1997). Others have recently demonstrated that when maternal intake is reduced by $50 \%$ from day 30 to 70 of pregnancy there is in an increased ratio of oxidative to glycolytic muscle fibre type in 2 week old lambs (Fahey et al. 2005). Similar nutritional restriction in early pregnancy has also been demonstrated to increase fat mass in postnatal sheep (Symonds et al. 2005). Thus nutrition in early pregnancy may also determine important aspects of both prenatal growth and body composition that may not necessarily be reflected in altered size at birth.

Growth rate of twins in late gestation is less than that of singletons and is often discordant within the twin pair. If fetal growth has important associations with fetal and postnatal development, studying twins may provide insights into these associations. We recently presented data that demonstrate complex interactions in twin sheep between periconceptional nutrition, twinning and fetal growth responses to maternal undernutrition in late gestation (Bloomfield et al. 2005). In response to a 3 day maternal fast in late gestation, the heavier sheep fetus of a twin pair whose mother was well nourished around conception does not reduce its growth rate, thereby behaving in a similar manner to a singleton fetus whose mother was undernourished during the periconceptional period. The lighter twins of both the periconceptionally well nourished and undernourished groups do slow their growth dramatically in response to maternal fasting in late gestation. We speculate that the placenta serving the lighter twin may have less functional capacity to maintain fetal growth. In contrast, the heavier twin of the periconceptionally undernourished group initially slows its growth in response to maternal fasting in late gestation in a similar manner to the lighter, undernourished twin, but then returns to its original growth rate. The placenta serving the heavier twin presumably has better placental functional capacity to adapt to maternal restriction and is therefore able to allow the fetus to maintain its original growth rate. These conclusions are supported by changes in the circulating concentrations of glucose, lactate, urea and amino acids in the fetus during the course of nutritional manipulations (Bloomfield et al. 2005). We suggest that these data support two important concepts: firstly, that aspects of twin growth and metabolism are also determined around the time of conception and, secondly, that there may be important interactions between periconceptional events and subsequent placental functional capacity. This may be causal in determining the 
relative size of twins within a pair, but may also determine the ability of the placenta to supply the fetus with nutrients in the face of reduced maternal nutrient supply. The concept of placental capacity being determined in early pregnancy is supported by elegant data from Kwong et al. who demonstrated that the proportion of inner cell mass which is allocated to the trophoblast and thus the placenta can be affected by the prevailing nutrient environment in the periconceptional period (Kwong et al. 2000), thereby emphasizing the critical nature of this period of pregnancy.

The consequences of periconceptional undernutrition for postnatal growth and development of singleton and twin sheep are now under study. Preliminary data from our laboratory show that in the period from birth to 3 months, weight gain was greater in singleton lambs from ewes undernourished in the periconceptional period (Fig. 1) despite the fact that milk intake was not increased. Insulin like growth factor 1 (IGF-1), an important marker of growth in young animals, was also higher in the same lambs throughout the same period. However, weight at 4 months of age was similar in both groups, suggesting an altered pattern of early postnatal growth after periconceptional undernutrition. Twinning obscured any effect of periconceptional undernutrition on weight gain and IGF-1 levels. The long term effects of periconceptional undernutrition on important production parameters such as the development of muscle and fat requires further investigation.

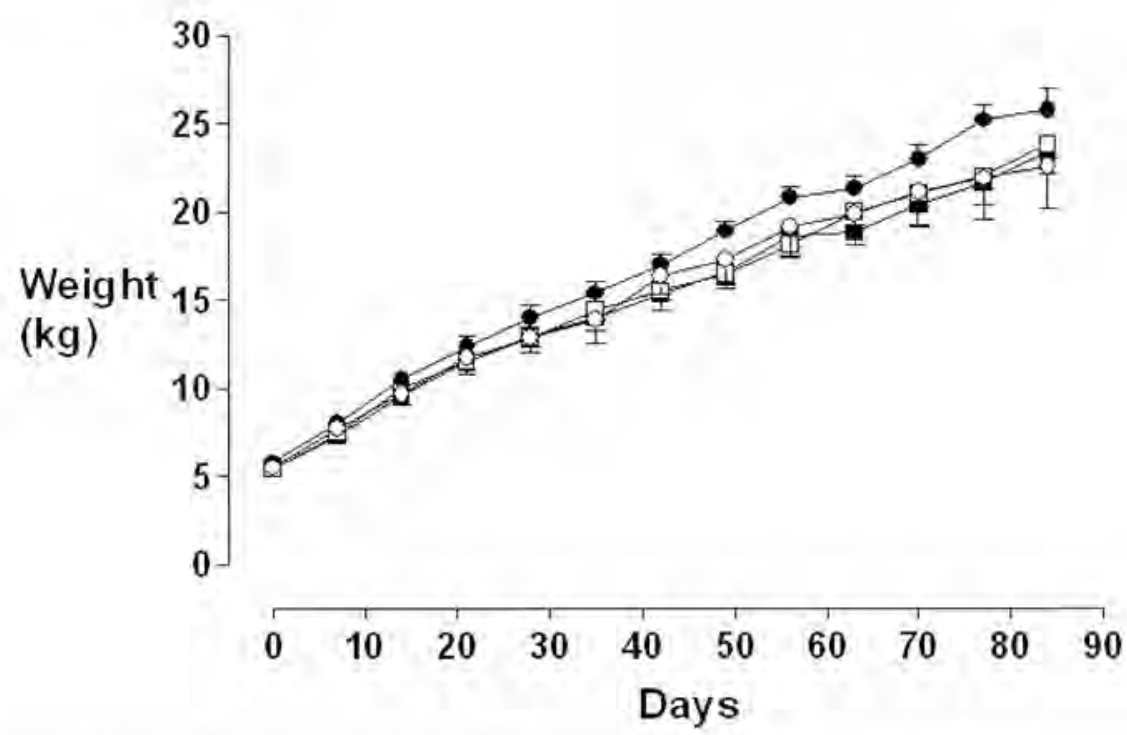

Figure 1. Weights of lambs from birth until weaning (means \pm SEM), Singleton lambs born to ewes undernourished from $60 \mathrm{~d}$ before, to $30 \mathrm{~d}$ after mating (closed circles, $n=10$ ) increased in weight faster than singleton lambs born to ewes well fed during the same period (open circles, $n=6, p<0.05$, multiple linear regression). There was no difference between twin lambs born to ewes undernourished from $60 \mathrm{~d}$ before, to $30 \mathrm{~d}$ after mating (closed squares, $n=13$ ) and those born to ewes well fed during the same period (open squares, $n=21$ ).

\section{Timing of birth and HPAA development}

We have also reported that moderate maternal undernutrition in the periconceptional period (individual feed intake adjusted to reduce maternal weight by $10-15 \%$ from $60 \mathrm{~d}$ before until 
$30 \mathrm{~d}$ after mating) reduces the mean gestation length of singleton-bearing ewes by $8 \mathrm{~d}$ (Bloomfield et al. 2003). None of these preterm lambs survived, despite being appropriately sized for gestational age and being born indoors. More detailed physiological tests and molecular studies in a parallel cohort killed in late gestation revealed that periconceptional undernutrition had led to precocious activation of the fetal HPAA, resulting in premature elevation of fetal plasma ACTH, cortisol (Bloomfield et al. 2004a) and prostaglandins PGE2 and PGFM (Kumarasamy et al. 2005), thus resulting in earlier onset of parturition (Fig 2.). Subsequent studies in human populations have also suggested that nutrition before and in early pregnancy affects the length of gestation, with maternal dieting, eating disorders (Cnattingius et al. 1998; Sollid et al. 2004) and early pregnancy vomiting being associated with an increased risk of preterm birth (Dodds et al. 2006).
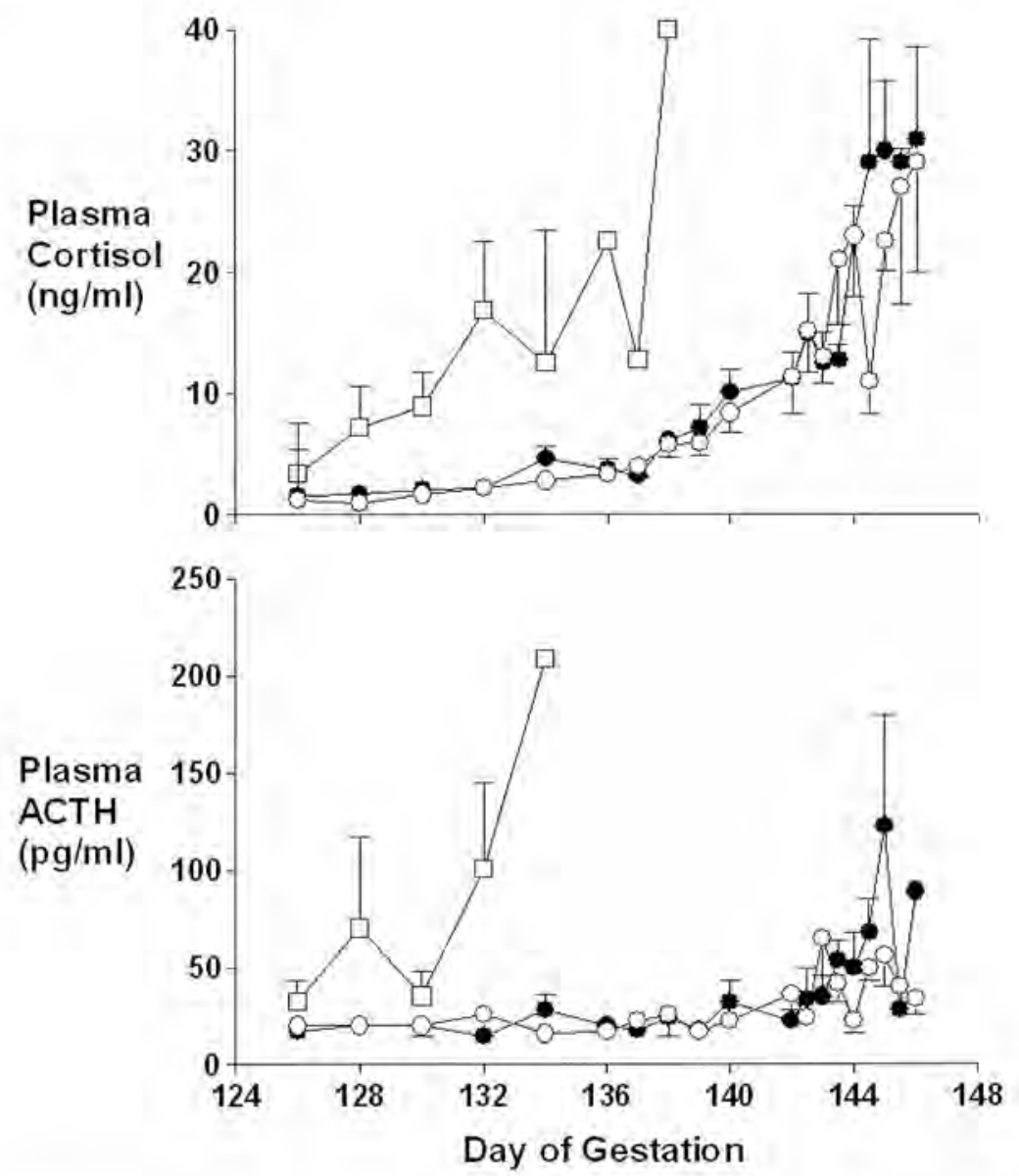

Figure 2. Fetal plasma cortisol and ACTH concentrations from $125 \mathrm{~d}$ until delivery. Lambs born prematurely to ewes undernourished from $60 \mathrm{~d}$ before, to $30 \mathrm{~d}$ after mating (open squares, $n=5$ ) had an early rise in plasma cortisol and ACTH concentrations. Term lambs born to ewes underfed from $60 \mathrm{~d}$ before, to $30 \mathrm{~d}$ after mating (closed circles, $n=5$ ) or ewes well fed during the same period (open circles, $n=8$ ) had later increases in plasma cortisol and ACTH concentrations (both $p<0.01$, ANOVA). 
These findings have important implications for the livestock industry. Early birth of an appropriately sized lamb may not be recognised within the paradigm of normal farm-based breeding practices, and subsequent death may be ascribed to causes in the immediate environment at birth rather than nutrition of the mother five or more months earlier. Such effects may perhaps be reflected in the high lamb mortality rates that are a regular feature of the pastoral sheep farming industry in New Zealand. It is also widely recognised that multiple lambs are born smaller and earlier making them more vulnerable.

Apart from an increased risk of prematurity, precocious activation of the HPAA has wider implications for the postnatal health, growth and performance of the production animal. Cardiovascular and metabolic homeostasis are profoundly influenced by central HPPA activity and also by expression of glucocorticoid receptors (GR) and $11 B$-hydroxysteroid dehydrogenase (11B-HSD) isoforms in the peripheral tissues. The action of 11 B-HSD-1 is to activate cortisol from cortisone while 11ß-HSD-2 works in the other direction. Others have shown that early gestation undernutrition results in increased fat deposition in postnatal lambs (Symonds et al. 2005) and it is likely that this could be mediated by changes in the expression and interaction of leptin, GR and 11B-HSD isoforms in adipose tissues (Budge et al. 2005). Increased adipose expression of GR and 11B-HSD-1, but decreased expression of $11 \mathrm{~B}-\mathrm{HSD}-2$, is observed in obese humans (Budge et al. 2005). Leptin levels in the circulation are strongly correlated with fat mass and chronic administration of the hormone in rats results in increased adipose expression of GR and 11ß-HSD-1, and decreased expression of 11B-HSD-2 (Gnanalingham et al. 2005).

We have recently shown that ACTH and cortisol responses of 10 month old female sheep to a combined $\mathrm{CRH}$ and AVP challenge are inversely related to birth weight in both singletons and twins, but the birth size effect was greater in twins (Bloomfield et al. 2004b). These findings raise the possibility that HPAA function in relation to size at birth may have important implications for both animal production and carcass composition of twins.

\section{Insulin secretion and signalling}

The development of impaired glucose tolerance, and ultimately frank diabetes, is thought to arise from a combination of impaired insulin secretion and insulin resistance, although the relative contributions of these two phenomena are not always clear. The human epidemiological studies have been primarily focused on insulin resistance (Phillips et al. 1994; Osmond \& Barker 2000), although there is also clear evidence of pancreatic beta cell dysfunction (Hales et al. 1991; Fall et al. 1998). Our own sheep studies demonstrate that both insulin secretion (Oliver et al. 2001) and insulin signalling (Buckley et al. 2005) may be influenced by periconceptional undernutrition, and that the early changes are evident before birth.

In the fetus, as in the adult, pancreatic beta cells secrete insulin in response to a variety of stimuli including glucose and amino acids such as arginine (Fowden 1980). Pancreatic maturation in the late gestation fetus is characterised by increasing responsiveness to glucose (Aldoretta et al. 1998). Late gestation fetuses whose mothers were undernourished in the periconceptional period appear to have advanced pancreatic maturation, as evidenced by exaggerated insulin response to glucose but not arginine challenge (Oliver et al. 2001). This apparent accelerated maturation is consistent with the precocious development of the HPAA, described above, suggesting that nutritional status around the time of conception sets the trajectory of growth and maturation of a number of organ systems, It would be surprising, therefore, if these changes did not lead to altered postnatal physiology, but the results of such studies are not yet available.

One possible mechanism underlying the effects of undernutrition involves altered supply of 
specific nutrients critical to developing organ systems, Taurine may be one such nutrient; a semi essential amino acid that plays a key role in pancreatic cell development. Rats fed a low protein diet ( $9 \%$ vs $18 \%$ in controls) during pregnancy have low circulating taurine levels and give birth to offspring with impaired pancreatic beta cell function (Cherif et al. 1998). Insulin secretion can be normalised in the offspring by supplementing the maternal low protein diet with taurine during pregnancy. In sheep, the initial depression in maternal plasma concentrations of taurine during periconceptional undernutrition is followed by an elevation in maternal and fetal levels in late gestation, long after the mother has been returned to a normal diet. In the same fetuses pancreatic maturation is advanced, suggesting a possible link between fetal taurine levels and pancreatic development (Oliver et al. 2001).

The other component of impaired glucose tolerance is insulin resistance. In the rat, maternal protein restriction (Snoeck et al. 1990) or prenatal exposure to glucocorticoids of maternal or exogenous origin (Nyirenda et al. 2001) result in insulin resistance in the adult offspring. Paradoxically there is often an initial increase in insulin sensitivity in the offspring of exposed mothers in early life followed by a progressive deterioration as they age (Petry et al. 2000). The initial increase in insulin sensitivity is associated with elevations in the message and protein expression of key insulin signalling proteins. Consistent with this, we have evidence that levels of protein kinase- $\zeta$ (PK- $\zeta$ ), a key insulin signalling protein, are elevated in the muscle of late gestation sheep fetuses whose mothers were undernourished around the time of conception (Buckley et al. 2005). The postnatal consequences of advanced pancreatic maturation and altered insulin sensitivity during fetal life are currently under investigation.

\section{Physiological and metabolic regulation in the fetal/placental unit}

One mechanism by which periconceptional undernutrition may result in altered fetal growth and maturation may involve altered development of the placenta and hence feto-placental metabolic interactions. In rats, a maternal low protein diet in the $4.5 \mathrm{~d}$ period before implantation results in altered distribution of cells between the inner cell mass and trophectoderm of the blastocyst, and hence to the future embryo and placenta respectively (Kwong et al. 2000). Such embryos also show subtle alterations in substrate metabolism with altered glucose consumption and lactate production. Altered substrate metabolism is also evident in late gestation in fetal sheep after periconceptional undernutrition. Plasma lactate concentrations are higher while blood oxygen content and $\mathrm{pH}$ are lower than in fetuses from well nourished ewes, and the fetoplacental unit appears to convert a greater proportion of available glucose into lactate (Oliver et al. 2005). This may represent a means of conserving carbohydrate in the fetal compartment.

It is tempting to speculate that altered balance of the development of oxidative and glycoIytic pathways may be reflected in the finding that 2 week old lambs whose mothers were fed $50 \%$ of requirement from day 30 to 70 have reduced fast twitch, or glycolytic muscle fibres and more slow twitch, or oxidative fibres (Fahey et al. 2005).

Another example of altered feto-placental metabolism after periconceptional undernutrition involves serine and glycine metabolism. Glycine is an important substrate for the growing fetus, being essential for the synthesis of such critical end products as DNA, RNA, heme, bile salts, collagen and glutathione (Jackson 1991). In postnatal life there is considerable capacity for glycine synthesis, but during pregnancy demand may exceed maternal synthetic capacity, especially when nutrition is poor (Jackson et al. 1997). In both human and sheep pregnancy, glycine and serine do not cross the placenta in appreciable amounts, and so the feto-placental unit must synthesise most of its requirements by complex interconversion pathways between serine and glycine in the placenta and the fetal liver (Cetin et al. 1991). We have found that 
these pathways are perturbed in late gestation fetuses of ewes who had been undernourished in the periconceptional period. The ratio of serine to glycine in the fetal circulation was increased, in association with decreased activity in the placenta of one of the enzymes involved in serine and glycine interconversion, serine hydroxymethyltransferase (SHMT) and increased SHMT activity in the fetal liver (Fig 3.) (Thorstensen et al. 2005). The long term postnatal consequences of this imbalance remain to be determined.

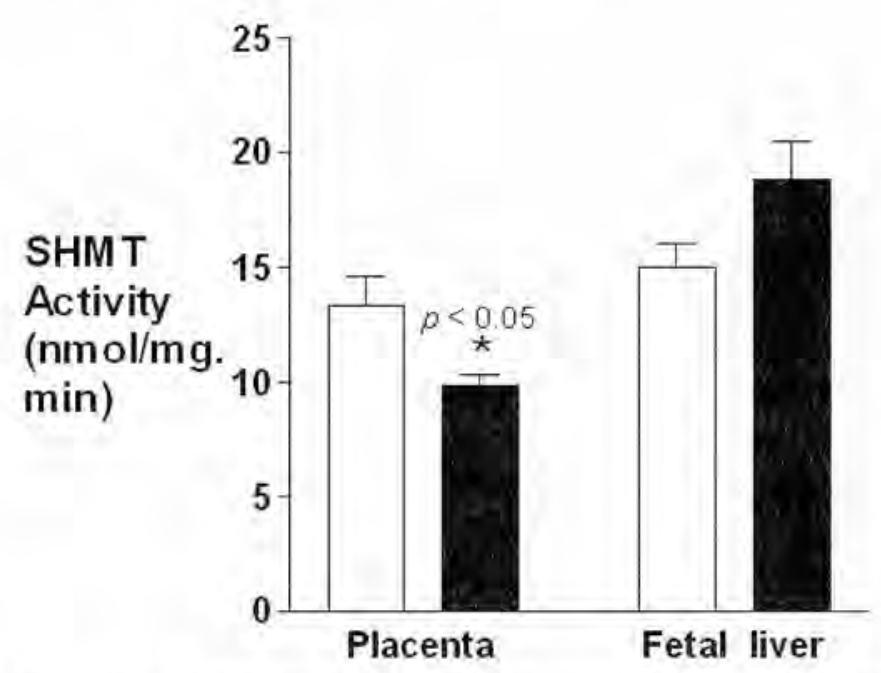

Figure 3. Placental and fetal hepatic serine hydroxymethyltransferase (SHMT) activity in $131 \mathrm{~d}$ sheep fetuses. Placentas from ewes underfed from $60 \mathrm{~d}$ before, to $30 \mathrm{~d}$ after mating (dark bars, $n=10$ ) had lower SHMT activities than those from ewes well fed during the same period (open bars, $n=9, p<0.05$, unpaired T-test). In contrast, SHMT activity tended to be higher in livers of fetuses whose mothers were underfed from $60 \mathrm{~d}$ before, to $30 \mathrm{~d}$ after mating $(p=0.07)$.

\section{Altered maternal adaptation to pregnancy}

Much of the research concerning the relationship between size at birth and disease risk in adulthood has focused on the growth, physiology and endocrinology of the developing conceptus. There has been much less attention paid to possible alterations in maternal physiology and endocrinology that may give rise to such effects. In the case of periconceptional undernutrition, we have evidence from our sheep studies that several maternal hormonal and metabolic regulatory systems are altered and remain affected long after correction of the original nutritional deficit.

Excess exposure to maternal glucocorticoid has long been suggested to be the mediating factor in nutritionally-induced adaptive changes in fetal and postnatal development. This could happen in several ways. Firstly, undernutrition may be a stressor resulting in an elevation in maternal glucocorticoids, which then cross the placenta and lead to fetal exposure to excess glucocorticoids (Benediktsson et al, 1993; Cleasby et al. 2003). Secondly, activity of 11-ßHSD 2 , the enzyme that normally inactivates glucocorticoids, could be reduced in the placenta as a result of maternal undernutrition (Lesage et al, 2001) so that more maternal glucocorticoid reaches the fetus. Thirdly, 11-BHSD-1 the enzyme that activates cortisone to cortisol (or corticosterone in rodents), could be increased in the placenta or fetus in response to maternal 
undernutrition (Seckl et al. 1995), again resulting in increased fetal exposure to active glucocorticoid. Rats fed a low protein diet (9\% vs $18 \%$ in controls) during pregnancy exhibit increased corticosterone levels and give birth to pups of reduced birth weight, reduced glucose tolerance and elevated blood pressure as adults (Langley-Evans 1997a; Seckl \& Meaney 2004). These same findings can be reproduced by administration of synthetic glucocorticoids or by direct inhibition of 11 B-HSD-2, and prevented by maternal adrenalectomy to prevent the rise in maternal glucocorticoids in response to nutritional stress (Langley-Evans 1997b). Similarly, synthetic glucocorticoid administration on day 28 of pregnancy in sheep results in hypertension of the offspring (Dodic et al. 1998), and reduced birth size in human pregnancy is associated with decreased placental activity of 11B-HSD-2 (Hofmann et al. 2001).

We hypothesised that the effects of periconceptional undernutrition in sheep may likewise be mediated by the elevation of maternal glucocorticoid levels in response to the "stress" of undernutrition. However contrary to our hypothesis, we found that there was a marked decrease in maternal plasma cortisol and ACTH concentrations during prolonged but moderate undernutrition (Bloomfield et al. 2004a). Similar findings have been reported elsewhere in slightly different undernutrition experiments (Edwards \& McMillen 2001; Bispham et al. 2003). We went on to show that undernutrition was associated with an increased ACTH response to $A V P+C R H$ challenge but a decreased cortisol response, suggesting that the suppression of the maternal HPAA by periconceptional undernutrition may result in adrenal ACTH resistance (Jaquiery et al, 2006). Interestingly we found that even after $20 \mathrm{~d}$ of refeeding (day 50 of pregnancy), that maternal adrenal mRNA levels of the ACTH receptor, steroidogenic acute regulatory protein (a key regulator of cholesterol transport in steroid synthesis) and P450c17, the rate limiting enzyme in cortisol production, were all still reduced and circulating maternal cortisol levels were also still low. Thus it is possible that the accelerated maturation of fetal physiology and endocrinology that we observed may result from development in a low, rather than high, maternal glucocorticoid environment during the first half of pregnancy. However placental 11-ßBHSD 2 activity was also decreased in these animals, raising the possibility that the fetus could be exposed to excess maternal glucocorticoids later in pregnancy if maternal adrenal function recovered while placental enzyme activity remained low. Further studies in late gestation are currently under way to address this question.

Other aspects of maternal endocrinology were also markedly perturbed after periconceptional undernutrition. Progesterone levels were reduced from $10 \mathrm{~d}$ after mating until 80-90 d of gestation (Bloomfield et al. 2004a). This may reflect impaired function of the corpus luteum, and potentially delayed transfer of progesterone production to the placenta in mid pregnancy. Others have shown that elevation of maternal progesterone levels for the first $3 \mathrm{~d}$ of pregnancy have a profound impact on local hormone production and embryonic, fetal and placental growth (Kleemann et al. 2001). Plasma placental lactogen (PL) concentrations were reduced in periconceptionally undernourished ewes for the last half of pregnancy (Bloomfield et al. 2004a). It is suggested that PL in the maternal circulation promotes lipolysis (Thordarson et al. 1987) and insulin resistance (Ryan \& Enns 1988), thereby favouring transfer of nutrients to the placenta and fetus. Thus impaired production of PL may be another mechanism whereby periconceptional undernutrition may perturb fetal growth and metabolism in late gestation. Our finding that the feto-placental unit in these animals may convert a greater fraction of glucose to lactate as a means of carbohydrate conservation (Oliver et al. 2005) may also be consistent with this.

The development of moderate insulin resistance is a normal physiological adaptation to pregnancy, thought to contribute to sparing of maternal glucose supply to meet the high fetoplacental demand. In human pregnancy, impaired development of insulin resistance is associated with impaired fetal growth (Catalano et al. 1995; Bernstein et al. 1997; Caruso et al. 
1998). In sheep, we have found that maternal undernutrition from $60 \mathrm{~d}$ before to $30 \mathrm{~d}$ after conception impaired development of insulin resistance of glucose and fat metabolism in the mother at $65 \mathrm{~d}$ gestation, and that the effects on fat metabolism were still present at $120 \mathrm{~d}$ gestation (Jaquiery et al. 2005). Preliminary data suggest that impaired development of pregnancy associated insulin resistance does not occur if the ewe is well fed until mating and only subjected to undernutrition for the first $30 \mathrm{~d}$ of pregnancy. The mechanisms underlying the development of insulin resistance in pregnancy, and thus their impairment with periconceptional undernutrition, are not yet clear. However the changes in progesterone and placental lactogen described above may both be contributory (Ryan \& Enns 1988), and other mechanisms remain to be explored.

\section{Consequences of periconceptional undernutrition for the postnatal animal}

Human epidemiological studies suggest that cardiovascular disease, hyperlipidaemia and obesity are all increased in adults whose mothers were exposed to undernutrition in early pregnancy (Roseboom et al. 2001a). In a normal pastoral farm setting, premature birth of domestic livestock due to periconceptional undernutrition would result in neonatal death, precluding a postnatal outcome. There are a limited number of studies that have investigated postnatal outcomes in sheep after maternal undernutrition in early to mid pregnancy. Hansen and colleagues demonstrated that maternal undernutrition from mating until day 70 of pregnancy resulted in lambs with moderate hypertension (Hawkins et al. 2000) and an enhanced cortisol response to ACTH both in late gestation (Hawkins et al. 2001) and in early postnatal life. Similar regimes of maternal undernutrition result in postnatal lambs with increased fat mass, leptin mRNA expression (Symonds et al. 2005) and an increase in the ratio of oxidative/slow twitch to glycolytic fast twitch muscle fibres in two week old lambs (Fahey et al. 2005). In the rat maternal low protein diet in the pre-implantation period resulted in reduced birth weight and postnatal hypertension (Kwong et al. 2000).

There are also some preliminary data emerging suggesting altered postnatal physiology in twins compared to singletons. Juvenile twin lambs, up to 6 months of age, appear to be more insulin sensitive than singletons and this is related to being the lighter of the twin pairs (Clarke et al. 2000). We did not find any difference in post pubertal glucose tolerance in post-pubertal twin lambs, and this may reflect the switch from increased sensitivity to progressive resistance referred to earlier. However, post pubertal female twins do have increased HPAA activity compared to singletons, and once again the lighter of a twin pair had the higher activity (Bloomfield et al. 2004b). Data are also emerging from human studies suggesting differences between twins and singletons. For example, insulin sensitivity is reduced in 7 year old twins compared to singletons (Jefferies et al. 2004) and glucose tolerance in adult Danish twins is reduced in the lighter of the twin pairs (Poulsen \& Vaag 2006). Unfortunately most studies in twins suffer from the lack of an appropriate control group and from subject selection; more well designed studies in both humans and animals are urgently needed to confirm or refute these preliminary observations.

The above findings may have important implications for the livestock industry. Premature birth and reduced neonatal survival are very costly problems for the industry. Alterations in muscle differentiation, insulin secretion and signalling, and HPAA regulation at the hormonal and tissue level are also likely to have important consequences for health, growth, composition and productivity of farm animals. Many studies have manipulated maternal nutrition during pregnancy, beginning well after conception and often also well after implantation. Our studies suggest that nutrition before and immediately after mating may have important consequences 
for the growth and development of the offspring, its survival at birth, and its subsequent health and productivity.

\section{Conclusions}

Maternal undernutrition during the periconceptional period has important effects on the growth and development of the offspring in utero and there are an increasing number of epidemiological and experimental studies that suggest there are profound effects on the health of those offspring after birth. The length of pregnancy can be perturbed by poor maternal nutrition during the periconceptional period and there are also increased risks of obesity, diabetes and heart disease in postnatal life. The challenge in medical science is to develop better understanding of optimum nutrition in the periconceptional period and to develop methods for detecting and treating perturbed development to reduce adverse consequences. In the livestock production industry, a better understanding of the impact of maternal nutrition during the periconceptional period on the growth, health and production characteristics of the offspring will allow an opportunity to intervene in a way that is unparalleled in human medicine.

\section{Acknowledgements}

We would like to acknowledge the valuable input of our colleagues Bernhard Breier, Alexandra Buckley, John Challis, Nina DeBoo, Peter Gluckman, Paul Hawkins and Murray Mitchell. Our studies would not have been possible without the excellent technical assistance of Christine Keven, Toni Mitchell, Samantha Rossenrode, Eric Thorstensen and Pierre Van Zjil. Our research is supported by the Health Research Council of New Zealand, National Research Centre for Growth and Development, New Zealand Lottery Board and The Lion Foundation.

\section{References}

Aldoretta PW, Carver TD \& Hay WW, Jr 1998 Maturation of glucose-stimulated insulin secretion in fetal sheep. Biology of the Neonate 73 375-386.

Barker DJ 2000 in utero programming of cardiovascular disease. Theriogenology 53 555-574.

Barnes FL 2000 The effects of the early uterine environment on the subsequent development of embryo and fetus. Theriogenology 53 649-658.

Benediktsson R, Lindsay RS, Noble I, SeckI IR \& Edwards CR 1993 Glucocorticoid exposure in utero: new model for adult hyperlension. Lancet $\mathbf{3 4 1} 339$ 341.

Bernstein IM, Goran MI \& Copeland KC 1997 Malernal insulin sensitivity and cord blood peptides: relationships to neonatal size at birth. Obstetrics and Gynecology 90 780-783.

Bispham J, Gopalakrishnan GS, Dandrea J, Wilson V, Budge $H$, Keisler DH, Broughton Pipkin F, Stephenson T \& Symonds ME 2003 Maternal endocrine adaptation throughout pregnancy to nutritional manipulation: consequences for maternal plasma leptin and cortisol and the programming of felal adipose tissue development. Endocrinology 1443575 . 3585.
Bloomfield $F H$, Oliver $M H$, Hawkins P, Campbell $M$, Phillips DI, Gluckman PD, Challis JR \& Harding IE 2003 A periconceptional nutritional origin for noninfectious preterm birth. Science 300606.

Bloomfield $\mathrm{FH}$, Oliver $\mathrm{MH}$, Hawkins P, Holloway AC, Campbell M, Gluckman PD, Harding JE \& Challis IR 2004a Periconceptional undernutrition in sheep accelerates maturation of the fetal hypothalamic-piluitary-adrenal axis in late gestation. Endocrinology 145 4278-4285.

Bloomfield FH, Oliver, MH, Harding, JE 2004b The importance of being a twin: within twin pair analysis of glucose tolerance and hypothalamic-pituitary-adrenal axis responsiveness. In Medical Sciences Collgress of New Zealand pp. C8. Queenstown.

Bloomfield $\mathrm{FH}$, Rumball $\mathrm{C}$, Oliver $\mathrm{MH}$, Jaquiery $\mathrm{AL}$, Harding JE 2005 Periconceptional undernutrition and twin size affect both growth and metabolic responses of twin sheep to an acute maternal fast in late gestation. In International Congress of Developmental Origins of Health and Disease. Pediatric Research 58(5) P3-032, Toronto.

Buckley Al, Oliver $\mathrm{MH}$, Bloomfield $\mathrm{FH}$, Harding IE 2005 Upregulated expression of $\mathrm{PKC} z$ in letal skel- 
etal muscle of periconceptionally undernourished ewes. In 3rd International Congress of Develop. mental Origins of Health and Disease. Pediatric Research 58(5) P1-038, Toronto.

Budge $H$, Gnanalingham MG, Gardner DS, Mostyn A, Stephenson T \& Symonds ME 2005 Maternal nutritional programming of fetal adipose tissue development: long-term consequences for later obesity. Birth Defects Research Part C Embryo Today 75 193-199.

Caruso A, Paradisi G, Ferrazzani S, Lucchese A, Moretti S \& Fulghesu AM 1998 Effecl of maternal carbohydrate melabolism on fetal growth. Obstetrics and Gynecology 92 8-12.

Catalano PM, Drago NM \& Amini SB 1995 Maternal carbohydrate melabolism and its relationship to fetal growth and body composition. American Journal of Obstelrics and Gynecology 172 1464-1470.

Cetin I, Fennessey PV, Quick AN, Jr., Marconi AM, Meschia G, Battaglia FC \& Sparks JW 1991 Glycine furnover and oxidation and hepatic serine synthesis from glycine in fetal lambs. American foumal of Physioliology 260 E371-378.

Cherif H, Reusens B, Ahn MT, Hoet II \& Remacle C 1998 Effects of laurine on the insulin secrefion of rat fetal islels from dams fed a low-protein diet lournal of Endocrinology 159 341-348.

Clarke L, Firth K, Heasman L, Juniper DT, Budge $\mathbf{H}$, Stephenson T \& Symonds ME 2000 Influence of relative size at birth on growth and glucose homeostasis in twin lambs during juvenile life. Reproduction Fertilility and Development 12 69-73.

Cleasby ME, Kelly PA, Walker BR \& SeckI JR 2003 Programming of rat muscle and fat metabolism by in utero overexposure to glucocorticoids, Endocrinology 144 999-1007.

Cnattingius S, Bergstrom R, Lipworth L \& Kramer MS 1998 Prepregnancy weight and the risk of adverse pregnancy outcomes. New England lournal of Medi. cine 338 147-152.

Dodds L, Fell DB, Joseph KS, Allen VM \& Butler B 2006 Outcomes of pregnancies complicated by hyperemesis gravidarum. Obstetrics and Gynecology 107285.292.

Dodic M, May CN, Wintour EM \& Coghlan JP 1998 An early prenatal exposure to excess glucocorticoid leads to hypertensive offspring in sheep. Clinical Science (lond) 94 149-155.

Edwards 니 \& McMillen IC 2001 Maternal undernutrition increases arterial blood pressure in the sheep fetus during late gestation. Journal of Physiology 533561.570 .

Fahey A], Brameld JM, Parr T \& Buttery PI 2005 The effect of maternal undernutrition before muscle differentiation on the muscle fiber development of the newborn lamb. Journal of Animal Science 832564 . 2571.

Fall CH, Osmond C, Barker DJ, Clark PM, Hales CN, Stirling Y \& Meade TW 1995 Fetal and infant growth and cardiovascular risk factors in women. British Medical Journal $310428-432$.
Fall CH, Stein CE, Kumaran K, Cox V, Osmond C, Barker DJ \& Hales CN 1998 Size at birth, maternal weight, and type 2 diabetes in South India. Diabetic Medicine 15 220-227.

Fowden AL 1980 Effects of arginine and glucose on the release of insulin in the sheep fetus. Journal of Endocrinology 85 121-129.

Gluckman PD, Hanson MA, Spencer HG \& Bateson P 2005 Environmental influences during development and their later consequences for health and disease: implications for the interpretation of empirical studies, Proceedings: Biological Sciences 272, 671-677.

Gnanalingham MG, Mostyn A, Webb R, Keisler DH, Raver N, Alves-Guerra MC, Pecqueur C, Miroux B, Symonds ME \& Stephenson T 2005 Differential effects of leptin administration on the abundance of UCP2 and glucocorticoid action during neonatal development. American Journal of Physioliology, Endocrinology and Metabolism 289 E1093-1100.

Hales CN, Barker DJ, Clark PM, Cox LJ, Fall C, Osmond C \& Winter PD 1991 Fetal and infant growth and impaired glucose tolerance at age 64. British Medical Journal 303 1019-1022.

Harding JE 1997 Periconceptual nutrition determines the fetal growth response to acute maternal undernutrition in fetal sheep of late gestation. Prenatal and Neonatal Medicme 2 310-319.

Hawkins P, Hanson MA \& Matthews SG 2001 Maternal undernutrition in early gestation alters molecular regulation of the hypothalamic-pituitary-adrenal axis in the ovine felus. Journal of Neuroendocrinology $13855-861$.

Hawkins P, Steyn C, Ozaki T, Saito T, Noakes DE \& Hanson MA 2000 Effect of maternal undernutrition in early gestation on ovine fetal blood pressure and cardiovascular reflexes. American fournal of Physiology 279 R340-348.

Hofmann M, Pollow K, Bahlmann F, Casper F, Steiner E \& Brockerhoff P 200111 beta-hydroxysteroid dehydrogenase (11 beta-HSD-II) activity in human placenta: its relationship to placental weight and birth weight and its possible role in hyperlension. Journal of Perinatal Medicine 29 23-30.

Jackson AA 1991 The glycine story. European Journal of Clinical Nutrition 45 59-65.

Jackson AA, Persaud C, Werkmeister G, McClelland IS, Badaloo A \& Forrester T 1997 Comparison of urinary 5-L-oxoproline ( $\mathrm{L}$-pyroglutamate) during normal pregnancy in women in England and Jamaica. British Journal of Nutrition 77 183-196.

Jaquiery $\mathrm{AL}$, Oliver $\mathrm{MH}$, Bloomfield $\mathrm{FH}$, Connor $\mathrm{KL}$, Challis JR \& Harding JE 2006 Fetal exposure to excess glucocorticoid is unlikely to explain the effects of periconceptional undernutrition in sheep. Journal of Physioliology 572 109-118.

Jaquiery AL, Oliver MH, Buckley A, Harding JE 2005 Effect of periconceptional undernutrition on insulin sensitivity at 65 days gestation in singleton bearing pregnant ewes. In 3rd International Congress of Developmental Origins of Health and Disease. Pediatric Research 58(5) P1-053, Toronto. 
Jefferies CA, Hofman PL, Knoblauch H, Luft FC, Robinson EM \& Cutfield WS 2004 Insulin resistance in healthy prepubertal twins. Journal of Pediatrics 144 608-613.

Kleemann DO, Walker SK, Hartwich KM, Fong L, Seamark RF, Robinson JS \& Owens JA 2001 Fetoplacental growth in sheep administered progesterone during the first three days of pregnancy. Placenta 22 14-23.

Kumarasamy V, Mitchell MD, Bloomfield FH, Oliver MH, Campbell ME, Challis JR \& Harding JE 2005 Effects of periconceptional undernutrition on the initiation of parturition in sheep. American Journal of Physiology 288 R67-72.

Kwong WY, Wild AE, Roberts P, Willis AC \& Fleming TP 2000 Maternal undernutrition during the preimplantation period of rat development causes blastocyst abnormalities and programming of postnatal hypertension. Development 127 4195-4202.

Langley-Evans SC 1997a Hypertension induced by foetal exposure to a maternal low-protein diet, in the rat, is prevented by pharmacological blockade of maternal glucocorticoid synthesis. lournal of Hypertension 15 537-544.

Langley-Evans SC 1997b Intrauterine programming of hypertension by glucocorticoids. Life Sciences $\mathbf{6 0}$ 1213-1221.

Law CM 1996 Felal and infant influences on non-insulin-dependent diabetes mellitus (NIDDM). Diabetic Medicine 13 549-52.

Lesage ], Blondeau B, Grino M, Breant B \& Dupouy IP 2001 Maternal undernutrition during late gestation induces fetal overexposure to glucocorticoids and intrauterine growth retardation, and disturbs the hypothalamo-pituitary adrenal axis in the newborn rat. Endocrinology 142 1692-1702.

Nyirenda MJ, Welberg LA \& Seckl JR 2001 Programming hyperglycaemia in the rat through prenatal exposure to glucocorticoids-fetal effect or maternal influence? Joumal of Endocrinology 170 653-660.

Oliver MH, Hawkins P, Breier BH, Van Zijl PL, Sargison SA \& Harding JE 2001 Maternal undernutrition during the periconceptual period increases plasma taurine levels and insulin response to glucose but not arginine in the late gestational fetal sheep. Endocrinology $\mathbf{1 4 2} 4576-4579$.

Oliver MH, Hawkins P \& Harding JE 2005 Periconceptional undernutrition alters growth trajectory and metabolic and endocrine responses to fasting in late-gestation fetal sheep. Pediatric Research $57591-598$.

Osmond C \& Barker DJ 2000 Fetal, infant, and childhood growth are predictors of coronary heart dis. ease, diabetes, and hypertension in adult men and women. Environmental Health Perspectives 108 Suppl 3 545-553.

Petry CI, Ozanne SE, Wang CL \& Hales CN 2000 Effects of early protein restriction and adult obesity on rat pancreatic hormone content and glucose tolerance. Hormone and Metabolic Research 32233 239.
Phillips DI, Barker DI, Hales CN, Hirst S \& Osmond C 1994 Thinness at birth and insulin resistance in adult life. Diabetologia 37 150-154.

Phipps K, Barker DJ, Hales CN, Fall CH, Osmond C \& Clark PM 1993 Fetal growth and impaired glucose tolerance in men and women. Diabetologia 36225 228.

Poulsen P \& Vaag A 2006 The intrauterine environment as reilected by birth size and twin and zygosity status influences insulin action and intracellular glucose melabolism in an age or time-dependent manner. Diabetes 55 1819-1825.

Ravelli AC, van der Meulen JH, Michels RP, Osmond C, Barker DJ, Hales CN \& Bleker OP 1998 Glucose tolerance in adults after prenatal exposure to famine: Lancet 351 173-177.

Ravelli AC, van Der Meulen JH, Osmond C, Barker D) \& Bleker OP 1999 Obesity at the age of $50 \mathrm{y}$ in men and women exposed to famine prenatally. American Journal of Clinical Nutrition 70 811-816.

Rayco-Solon P, Fulford AJ \& Prentice AM 2005 Differential effects of seasonality on preterm birth and intrauterine growth restriction in rural Africans. American Journal of Clinical Nutrition 81 134-139.

Roseboom TJ, van der Meulen JH, Osmond C, Barker DJ, Ravelli AC \& Bleker OP 2000 Plasma lipid profiles in adults after prenatal exposure to the Dutch famine. American Journal of Clinical Nutrition 72 1101-1106.

Roseboom TJ, van der Meulen JH, Ravelli AC, Osmond C, Barker DI \& Bleker OP 2001a Effects of prenatal exposure to the Dutch famine on adult disease in later life: an overview. Molecular and Cellular Endocrinology 185 93-98.

Roseboom TJ, van der Meulen JH, van Montfrans GA, Ravelli AC, Osmond C, Barker DJ \& Bleker OP $2001 \mathrm{~b}$ Maternal nutrition during gestation and blood pressure in later life, Journal of Hypertension 1929 34.

Ryan EA \& Enns L 1988 Role of gestational hormones in the induction of insulin resistance, Journal of Clinical Endocrinology and Metabolism 67 341-347.

Seckl JR, Benediktsson R, Lindsay RS \& Brown RW 1995 Placental 11 beta-hydroxysteroid dehydrogenase and the programming of hypertension. Journal of Steroid Biochemistry and Molecular Bioliogy 55 447-455.

Seckl JR \& Meaney MI 2004 Glucocorticoid programming. Annals of the New York Academy of Sciences $103263-84$.

Snoeck A, Remacle C, Reusens B \& Hoet II 1990 Effect of a low protein diel during pregnancy on the fetal rat endocrine pancreas. Biology of the Neonate 57 107-118.

Sollid CP, Wisborg K, Hiort I \& Secher NJ 2004 Eating disorder that was diagnosed before pregnancy and pregnancy outcome. American fournal of Obstetrics and Gynecology $190 \quad 206-210$.

Symonds ME, Budge $\mathrm{H}$, Stephenson T \& Gardner DS 2005 Experimental evidence for long-term programming effects of early diet. Advances in Exerimental 
Medicine and Biology 569 24-32.

Thordarson G, McDowell GH, Smith SV, lley S \& Forsyth IA 1987 Effects of continuous intravenous infusion of an ovine placental extract enriched in placental lactogen on plasma hormones, metabolites and metabolite biokinetics in non-pregnant sheep. Journal of Endocrinology 113 277-283.

Thorstensen EB, Van Zijl P, Oliver MH, Harding JE 2005 Periconceptional undernutrition perturbs serine and glycine metabolism in the pregnant sheep. In The 9th annual congress of the Perinatal Society of Australia and New Zealand. 